\title{
Study on Market Regulation from the Government Regulation Innovation Perspective
}

\author{
Hui Liu \\ China National Institute of Standardization, Beijing, 100191, China. \\ Liuhui2604@163.com
}

\begin{abstract}
Keywords: Government regulation, regulation model, regulation mechanism, problems and countermeasures.
\end{abstract}

\begin{abstract}
China's national institution reform in this round, intends to carry out the unified market regulation, and establish a unified, open and modern market system with orderly competition, through the establishment of State Administration for Market Regulation. Besides, it is of great importance in better handling the relationship between government and market and better playing the role of government by clearly defining the reasonable boundaries of governmental regulation. At present, it is a trend for developed countries to loosen the economic regulation, but the social regulation becomes much stricter. There are mainly three market regulation models respectively represented by USA, EU, and Japan in this world. In terms of the present economic \& social changes, civil rights awareness, regulation weak links, regulation pressure and other aspects, this paper focuses on the analysis of the new challenges that China's market regulation is facing, and also presents the countermeasures and suggestions about how to realize the innovation of market regulation mechanism.
\end{abstract}

\section{Introduction}

The government regulation on market can be traced back to the Europe in 16th century. During the long period from 16th century to the end of 19th century, the public knowledge about regulation is mainly affected by the classical liberalism economic thoughts, believing that market itself will solve any problem, and proposing that the government shall be the negative "night-watchman-state government". Its representative figure Adam Smith firmly believes that market may convert the self-interested behavior of "Economic Man" to the common social welfare, and the market itself will solve any problem [1]. With the surge of productive forces brought by the second industrial revolution, the intrinsic defects of market are exposed due to the rapid economic development. For the sake of the public interest, the government shall come forward to solve the series problems caused due to the market failure. Therefore, regulation becomes one of the significant functions of modern government.

Since the "reform and opening-up" is enforced, Chinese government has attached great importance to its own market regulation function. As one of the four major functions of government, the market regulation function is first proposed at the Party's 16th Party Congress. At the Third Plenary Session of the 18th CPC Central Committee held in 2013, "strengthening the market regulation function of local government" is stressed in the Decision adopted at the Third Plenary Session of the 18th CPC Central Committee. At present, China is still continuously perfecting the socialist market economic system, while the government is also gradually transforming its role from "steering" to "rowing" [2]. The Decision proposes "reforming the market regulation system and enforcing the unified market regulation". The Opinions of the State Council on Promoting Fair Market Competition and Maintaining the Normal Market Order (No. 20 [2014] of the State Council) points out "Speeding up the reform on the market regulation system of county-level governments and exploring to comprehensively establish the market regulation institutions". All of these determine the basic principle of reform on China's market regulation system, "big market regulation" becomes the reform direction advocated at the state level. This round of the Institutional Restructuring of the State Council, will consolidate the relevant functions of the State Administration for Industry and Commerce, General Administration of Quality Supervision, Inspection and Quarantine, China Food 
and Drug Administration, National Development and Reform Commission, Ministry of Commerce, and Office of the Anti-monopoly Committee of the State Council, to establish the State Administration for Market Regulation, which intends to enforce the unified market regulation, and establish a unified, open and modern market system with orderly competition.

\section{Government Regulation and its Boundary}

The regulation refers to that the government uses the "binding force" resources to impose the mandatory limitation upon the individual or organization's free decision, while government regulation refers to apply such binding force to limit the decision-making of economic entity [3]. As one of the three levers of national formal rights in parallel with financial policy \& monetary policy, the government regulation is essential in economy and social welfare aspects [4]. The regulation is mainly adopted to correct the voluntary allocation offsets caused by market failure. However, it is repeatedly demonstrated by domestic \& overseas experiences that once the proper scope is exceeded, the government regulation will fail. Hence, it will facilitate the treatment of relationship between government and market, and the implementation of government function by clearly defining the reasonable boundaries of government regulation.

Chinese scholar Xun Mingli believes that the triple boundaries of government regulation, namely, value boundary, field boundary and efficiency boundary shall be defined [5]. The claim of social equality and justice is the first value boundary which shall be considered during the government intervention in market. Any government intervention act which is not made under the premise of social equality and justice, may worsen the unequal distribution of income, polarization of rich and poor, and other problems caused by market failure, which finally becomes the ineffective intervention. For the field boundary of government regulation, the government's public accountability system shall be made based on the overall principle of equalization of public services, and also fully consider how to take their own advantages of government and market in different fields. In the pure public goods sector, the government shall focus on the enhancement of accountability system of basic public services equalization, highlighting the compensation equality, instead of the transaction equality. In the quasi-public goods sector, the government shall take the lead in production, properly encourage the market supply, and perfect the accountability system of macro-economic control. In the private goods sector, the government shall fully play the decisive role of market and enhance the public accountability system of regulation market.

As to the category of market regulation, it generally falls into 2 categories, namely, regulation based on economic targets, and regulation based on social targets. The former mainly refers to government intervention in the market in case of the market failure, which is directly against the pricing, competition, market access \& withdrawal, and other market decision-making actions. However, the latter is intended to protect the security, health \& hygiene of labors \& consumers, and environment, and suppress the disaster. Besides, it will also develop certain criteria for the quality of materials \& services, and all sorts of activities associated with their provision, and forbid and restrict the special actions [6].

At present, there is a tendency that the developed countries will loosen the economic regulation. For instance, after the new Trump administration in USA comes into office, "loosening the government regulation \& seeking criteria support" policy is enforced in the relevant fields, so as to promote the employment and stimulate domestic economic growth. Shortly after taking the office, Trump orders to amend the 2022-2025 Automotive Fuel Efficiency Standards previously developed by Obama Administration, to loosen the regulation of environmental protection, stimulate the manufacturing development, and create jobs. American National Standards Institute is adopting the "standards will regulate the industrial development and promote the industrial self-discipline" series measures in drone, cyber security, digital economy, financial regulation, and other fields. The loosening of economic regulation is intended to loosen the straitjacket over enterprises and boost market dynamism. However, the continuous occurrence of consumer rights, food \& drug safety, 
ecological environment and other hazardous events related to public interests, will impose a serious threat upon the human existence, the harmony between human beings and nature, sustainable development, and other series of problems, and even threaten the social operation. Therefore, the unprecedented attention and reinforcement is made for the regulation of environmental protection, consumer rights, food safety, occupational safety, and other social fields [7]. In terms of the modern market regulation experiences, if it is related to security, consumer protection, environmental protection, and other fields where the major social public interests will be affected, the relevant market entities and their acts will be under the close regulation of government, while the market regulation based on administrative permission, approval and other strict regulation methods will be enforced.

\section{Main Patterns of Overseas Market Regulation}

As per the degree of state intervention and macro-economic control, the market regulations of each country at present can be generally divided into the following types:

Type one is the American-style market regulation. Under such a regulation system, the complete free market mechanism shall be enforced, while the freedom of market competition entity shall be fully safeguarded. The market completion entity shall be allowed to participate in all sorts of market competition, while the government shall provide the appropriate guidance. The reason is that the government's economic regulations will cause many problems and form a sort of burden to the economic development. Anyhow, the policy-making is subject to the special economic interests, or all sorts of lobby group. Based on this, "the government shall provide more guidance and development to the macro-economy and safeguard the fair market competition" [8]. The market regulation shall be achieved through giving full play to all sorts of social organizations, especially the self-regulatory organizations, which is called the self-regulation system.

Type two is the Germany-style market regulation. Under such a system, not only the leading role of government, but the strength of industrial organizations shall be used to participate in the market management. Specifically, government will put more emphasis on the adjustment of economic policy and the entire market, while the industrial organization will emphasize on the management of industrial market. "These industrial organizations account for $70-90 \%$ of the production scale of German industry, which are organized in an orderly, centralized and unified manner", to regulate the market [9], which is called the middle regulation system.

Type three is the Japanese-style market regulation. The government will fully dominate the market position. From the development \& enforcement of all sorts of industrial policy, to the maintenance of the market operation order, the government will play a significant role. Without the leading role of government, the market will become chaotic and disorder, which is called centralized regulation system.

The value target of the three systems mentioned above is consistent, namely, the effective market regulation will be used to promote the development of market economy and maintain the fair and orderly market competition environment. However, these three systems still have a certain variation in benefits pattern. The centralized regulation system focuses on satisfying the public interests and ensuring the equality, justice \& order of market, while the self-regulation system emphasizes on satisfying the interests of market participants. In a certain sense, the self-regulation system subjectively implies the potential self-interested targets, although such self-regulation objectively achieves the effects of maintaining the market equality and order. The middle regulation system has both features. Specifically, due to the leading role of government, the centralized regulation system makes the market regulation drift away from market competition, which further facilitates the exercise of market regulation function in a more efficient manner and ensures the objectivity and impartiality. However, its weakness is that due to the government's excessive intervention in the market, the market development is subject to excessive administrative intervention, which greatly restricts the functions of market mechanism itself. The outcome of the professionalism of 
self-discipline organizations and the self-discipline system of the industry itself, facilitates the self-regulation system to overcome the deficiency in the market development, while its efficiency is much higher than the centralized regulation system. For instance, due to the lower management efficiency, the American government relies on the social organization to manage the state-owned asset market, achieving the objective of enhancing the management efficiency [10]. Besides, as the self-discipline regulation focuses on the self-discipline function of ethnics, its involved fields are more extensive than the centralized regulation system, while its application scope is much wider. Its deficiency is that due to lacking of the unified regulation imposed by the Authoritative Institutions, its execution force is not adequate, which will even cause the dysfunctional competition among the self-discipline organizations, market segmentation, disorder, and failure. Meanwhile, due to the self-interest feature of self-discipline organization, its management detachability is not strong, which is hard to ensure the impartiality of management. Due to the combined advantages of the two systems mentioned above, the middle regulation system also overcomes its deficiency, which not only ensures the "surface" regulation of government, but also reflects the "point" management of industrial organizations, obviously enhancing the regulation efficiency. Therefore, it has much higher administrative efficiency and much wider application scope in the market regulation, which is commonly adopted by the EU at present.

\section{New Challenges China's Market is Facing at Present}

(1) The economic \& social change presents new requirements upon the market regulation. With the popularization and spread of "Internet Plus" idea, and the "Four New Economy", namely, new technology, new industry, new industrial format, and new pattern, much more and higher requirements are imposed upon the market regulation. The on-site, by phase, and by field law enforcement mechanism under the traditional regulation pattern has already been lagged behind, which is hard to adapt and match with the new requirements presented due to social change.

(2) The enhancement of civil rights awareness brings new challenge to market regulation. The common people's attention upon the product safety has been gradually increased, while the consumer rights-protection awareness and participation \& regulation awareness are also continuously enhanced. It is a typical case that China's industrial \& commercial departments and market regulation departments have dealt with 1.667 million complaints in 2016, with year-on-year growth of $29.1 \%$. This imposes the new challenge to both the market regulation at the middle end and the rights protection and treatment at the back end. Besides, it shall also be noticed that although some street vendor business activities are not completely legal in nature, they are still welcomed to some extent, due to the convenience they provide to the surrounding people. In case that the law enforcement is too simple and brutal, the public backlash may occur. Hereto, the combination of principle and flexibility shall be stuck to in the actual works. On one hand, the safety bottom line must be really kept, safeguarding the basic interests of the public. On the other hand, the case by case method and the principle of convenience for the masses shall be stuck, while the combination of blocking \& dredging, and management enforcement by types shall also be implemented.

(3) The regulation weak links and high-risk fields become highlighted, including not only the illegal operation of mobile vendors, unlicensed business activity and other traditional problems, but also cross-border online shopping, "Zombie Meat" and other new problems. For instance, due to the large quantity, small scale, many types, loose distribution, poor sanitation, disorderly purchase \& sales channel, varying quality of operators, and other reasons, food vendors become the long-standing problem of local market regulations.

(4) The rising regulatory pressure makes the regulation institution become exhausted. For one thing, there are a large number of market entities which are rapidly increased. Under the background of mass entrepreneurship and innovation, there are 15100 daily newly registered enterprises and 45100 daily newly registered market entities in 2016 . The greatly increased market entities not only unleash the economic dynamism and create jobs, but objectively put enormous strains on the market 
regulation. For the other thing, new style business formats are emerging endlessly. The online shopping and mobile client shopping have gradually become the mainstream, the subject \& spatial separation among the platforms, merchants, producers, consumers and logistics enterprises causes many troubles for the regulation enforcement and disposal of rights protection complaints.

\section{How to Realize the Innovation of Market Regulation Mechanism}

\subsection{To Accelerate the Forming of Integrated Market Regulation Working System}

In order to transform the market regulation manner, it is the first priority to accelerate the forming of integrated market regulation working system, break down the linear think set under the original system, speed up the deep integration after the system reform, and commonly build the big regulatory pattern. First, it is intended to realize the "integration" of law enforcement administration. Besides, the joint response and coordination system of law enforcement shall be established as per the requirements of State Council's deployment, which is intended to realize the "integration" of management of all links from the system design to the organization \& enforcement, eliminate the regulatory blind spots, and thoroughly work out the prominent problem of weak leadership of a central government. Second, it is intended to realize the "integration" of law enforcement procedures. At the national level, the unified administrative penalty procedures for market regulation shall be developed. At the local level, rules shall be developed at the earliest, realizing the unification of complaint and report disposal procedure. Third, it is intended to realize the "integration" of law enforcement platform. By adhering to the principle of "integrated advantages, unified standards, centralized logic and physical dispersion" principle, the locally unified law enforcement regulation information platform and public complaint \& report disposal platform system shall be established, completely solving the "information island" problem. Fourth, the deployment of comprehensive and professional regulation forces shall be optimized. At the district (county) level, it is suggested to give priority to the professional regulation, emphasizing on the discovery and disposal of major legal violation acts with higher professional requirements, and the potential safety hazards. At the township level, it is suggested to give priority to allocate the "General Practitioner", realizing the "jack of all trades, and comprehensive law enforcement", emphasizing on the discovery and disposal of general legal violation acts and the potential safety hazards. Thus, the combined comprehensive \& professional regulation system with two levels of deployment and different emphasis will be formed. The market regulatory department shall strengthen the comprehensive regulation operation training and speed up the education of qualified talents who adapts the new regulation pattern.

\subsection{To Fully Enforce the "Double Random, and One Open" Regulatory Pattern}

As per the requirements of State Council on Promoting Random Inspection, it is suggested that the relevant national department shall formulate the working rules for random check of market regulation at the earliest, ensuring that the system will be put in place. First, the legally prohibited items shall be highlighted and "listed". The legally prohibited items of the business entities and legally checked items of law enforcement department shall be thoroughly checked, while the random check items list shall be respectively developed by business lines. Besides, the inspection subject, basis, contents, procedure, and the corresponding legal responsibilities shall be defined. The check items list shall highlight the targets, and timely release to the public. Anything that is not regulated by laws, regulations and rules shall not be inspected without authorization. Second, "Double Random" shall be enforced by combining the business characteristics. The primary level market regulation department shall establish the detailed list of objects subject to random check and list of law enforcement inspectors as per the inspection items, which shall be duly and dynamically adjusted by combining the working practices. In case that the regulation and inspection shall be carried out upon the enterprises in the pilot regulation fields, except there is evidence or clue to prove the suspected violation of law, or complaints report, hidden danger report, the inspection objects and law enforcement inspectors shall be randomly determined from the "Double List". As to the towns with less law enforcement inspectors, the off-site checking and cross-checking may be executed at the district level. Third, the 
"moderate inspection" by defining the frequency and authority shall be enforced. It is suggested that the district-level market regulatory department rationally and independently determine the spot checking proportion and frequency based on the district reality and the requirements of State Council on "Moderate Inspection", not only ensuring the necessary spot check coverage and work force but prevent that the excessive inspection will exceed the primary-level tolerance capacity and affect the inspection efficiency. Those key units that have the larger qualify safety risks, lower credit level, or are listed into the "Blacklist" shall be spot checked and inspected with a much stronger force.

\subsection{To Rely on the Informatization and Innovate on the Intelligent Regulation Measures}

In order to enhance the efficiency, the modern market regulation must absorb the internet idea and technical regulation idea. Specifically, it is necessary to construct the share, connection and synchronization mechanism between platforms, and enhance the coordination regulation and intelligent regulation capacity, through the construction of online government affairs hall, operational and post-operational comprehensive regulation platform, public credit information service platform and other foundation platform. The real-time monitoring, remote regulation, mobile law enforcement and online case handling will be carried out for the activities of market entities, while the informatization will be relied on to realize the source traceable, whole process controllable, risk preventable, performance assessable, and public knowable objectives. When put into practice, the database and command center of law enforcement information shall be constructed as the hub, providing the mobile law enforcement terminals for the front-line law enforcement inspector, and constructing the remote audio and video monitoring platform. Besides, the cell-phone, computer and other equipment shall be utilized to realize the all-around real-time monitoring, find the market illegal acts in the first place, and also fix the audio, video and image evidences. Furthermore, the regulation objects, especially, the objects with higher risk and public concerns shall be accessed to the video monitoring platform, while the construction of sunshine kitchen, sunshine farmers market, and sunshine drugstore shall be promoted as a priority.

\subsection{To Strengthen the Joint Administration Idea, and Make the Multiple Subjects Participate in the Administration and Monitoring}

Whether the market regulation is put in place not only depends on the solo of administrative organs, but also the active involvement of social organizations, the public, enterprises and other parties, which will transform the government's closed, single dimensional belly-worship pattern in the traditional market regulation to the open to society and multi-coordination multi-governing pattern. The credit incentives, market evaluation, trade autonomy, public monitoring and other mechanisms shall be used to form the sound interactions among the regulatory institutions, industry associations, and consumer protection organizations, developing the rewards \& punishments system of industry credit evaluation. Meanwhile, the social forces are also utilized to realize the risk pre-alarming and effectively reduce the cost. In Shanghai, the industry associations, experts \& scholars, and other forces are introduced to the special equipment, medical device, adverse drug effects, and other high-risk fields that people pay a close attention to, which enhances the discovery and disposal capacity of risks and hidden dangers. In order to enhance the activeness and orderliness of the public involvement, Shanghai also takes measures to support the public to participate in the on-site supervision and inspection of key fields.

\subsection{To Promote the Enterprise Credit and Classification Regulation Reform}

It is suggested to further promote the construction \& application of classification regulation system which takes the credit regulation as the core, strengthen the social credit supervision, and actually realize the "credit keeper will be unimpeded while the credit loser will be impeded" regulation pattern. First, it is necessary to accelerate the construction of unified, open public credit information platform. It is suggested that Standardization Administration of the People's Republic of China shall speed up the development of public credit information accumulation specification and other series of national standards, together with the relevant departments. The local docking between "code storage", "natural persons data mart" and public credit information platform shall be accelerated, while the batch fuzzy query, classification statistic, bad credit information collection in other fields, enterprise credit 
evaluation and other functions shall be enhanced to realize the interconnection and sharing of public credit information, strengthen the foundation of social credit system, and support the market credit self-purification mechanism to play a decisive role. Second, it is suggested to promote the enforcement of classification regulation system which takes the credit as the core. It is necessary to establish the quality credit classification criteria and differential regulation items list, take the classification evaluation and targeted regulation measures to the regulation objects, and maximize the regulation efficiency with the limited regulation resources, as per the quality safety risk degree, and the entity responsibility and social credit performance conditions of the corporation. Meanwhile, the classification evaluation indicator system, classification evaluation model, and classification criteria and differential regulation item list, and others shall be incorporated into the informatization regulation platform, realizing the automatic and timely dynamic evaluation and adjustment, solve the difficulty of enforcing the classification regulation system, and promote the scientification and refinement of market regulation. Third, it is necessary to construct the social supervision, joint punishment, and joint suppression of credit loss pattern. It is suggested to expand the social supervision, strengthen the regulation on discredited corporations, and carry out the joint binding and penalty against the illegal and discredited people based on the "big market" comprehensive regulation functions. For the daily regulation, administrative permission, procurement tender, public resources exchange, qualification class rating, rewarding and appraising, financial cash arrangement and other works, the government shall search the discredited enterprise blacklist database, and take the joint penalty measures against the discredited enterprises listed into the blacklist as per their corresponding responsibilities, forming the good pattern that the entire society will jointly suppress the credit loss and promote the market entities to become honest and self-disciplined.

\section{Acknowledgements}

This research was financially supported by the President Foundation of CNIS (572018Y-5937) and National key research and development program (2016YFF0204206).

\section{References}

[1]. Adam Smith, An Inquiry into the Nature and Causes of the Wealth of Nations (Volume 2), The Commercial Press, 1983.

[2]. Xu Ming, Regulation System Reform of Big Market: Reflection and TranscendenceConstructing the New Pattern of Responsive Regulation, Social Scientist, 2017, (12). p.84-89.

[3]. Viscusi, W.K., J. M. Vernon, J.E. Harrington, Jr., Economics of Regulation and Antitrust, Cambridge: The MIT Press, 2005, P. 357.

[4]. OECD, OECD Recommendation on Regulatory Policy and Government, OECD,2011.

[5]. Xun Mingli, Three Frontiers of Government Intervention in Markets-From the Perspective of Public Responsibility, China Public Administration, 2016, (4): p.122-125.

[6]. [Japan] Masu Uekusa, Micro-Regulatory Economics, translated by Zhu Shaowen and others, China Development Press, 1992.

[7]. Wang Wei, The Legal Logic and System Mechanism of Market Regulation-Analysis Based on Business System Reform, The Law Press, 2016.

[8]. David B. Audretsl, The market and the state, New York University Press 1989, p9.

[9]. Iris A. hauswirth, Effective and efficient organizations, Physica-Verlagberg, 2006, P120.

[10]. IPCC. Carbon Dioxide Capture and Storage [EB/0L] .http//www.ipcc.ch / publications_and_ data /publications and data reports carhon dioxide htm. 2010-02-25. 